\title{
Comparison the Effectiveness of Acceptance and Commitment Therapy and Compassion Focused Therapy on the Quality of Life and Tendency to Betray in Married Students with Tendency to Infidelity

\author{
Haleh Sabouri', Eghbal Zarei²*, Abdolvahab Samavi ${ }^{3}$, Azita Amir Fakhraei ${ }^{4}$
}

\begin{abstract}
This study was conducted to compare the effectiveness of acceptance and commitment therapy (ACT) and compassion-focused therapy (CFT) on quality of life (QOL) and infidelity tendency in infidelity-prone married students. This is a quasi-experimental research project with an expanded research design. The statistical population consisted of married students studying at the Islamic Azad University, Sirjan Branch in the 2018-2019 academic year. Using convenience sampling, 45 people were selected and randomly divided into three groups of 15 people (i.e., two experimental groups and one control group). The first group received ACT and the second group received CFT. Data were collected using The World Health Organization Quality of Life: Brief Version (WHOQOL-BREF) (1996) and Attitudes toward Infidelity Scale (ATIS) (Whathley, 2006). Data were analyzed by repeated-measures ANOVA and Bonferroni post-hoc test. The results showed that both therapies were effective on QOL and its dimensions except for environmental health $(\mathrm{p} \leq 0.05)$. Moreover, according to the findings, CFT was more effective than ACT in terms of physical health and, conversely, ACT was more effective than CFT in terms of mental health and social communication. Furthermore, the results showed a positive effect of both therapies on infidelity tendency in the statistical sample ( $\mathrm{p} \leq 0.05)$. Meanwhile, ACT was more effective than CFT. Therefore, the use of both therapies improves the couple's QOL level as well as reducing their tendency to infidelity.
\end{abstract}

Keywords: Acceptance and commitment therapy, compassion-focused therapy, quality of life, infidelity tendency

\section{Introduction}

According to a general definition, marital infidelity is the violation of commitment in a two-person relationship that leads to the formation of degrees of emotional and physical intimacy with someone outside the relationship (Weeks, Gambescia \& Jenkins, 2003). Infidelity is considered one of the two major causes of divorce and the collapse of marriage (Nowak, Weisfeld, Imamoğlu, Weisfeld, Butovskaya, \& Shen, 2014). Men and women have different perceptions of their spouse's extra-marital relationship. Such a perception overshadows the emotional responses associated with their relationship (Kemer, Bulgan \& Çetinkaya-Yildiz, 2016). Numerous factors are involved in facilitating the infidelity tendency; e.g. insecure attachment styles (Khayat,

1. Department of General Psychology, Bandar Abbas Branch, Islamic Azad University, Bandar Abbas, Iran

2. Associate Professor, Department of Psychology University of Hormozgan, Bandar Abbas, Iran*Corresponding author email: eghbalzarei2010@yahoo.com

3. Associate Professor, Department of Educational Sciences, University of Hormozgan, Bandar Abbas, Iran

4. Department of General Psychology, Bandar Abbas Branch, Islamic Azad University, Bandar Abbas, Iran 
Atari, Karaei, 2018, Barata and Kane, 2005), maladaptive schemas (Zeigler-Hill, Green, Arnau, Sisemore, Myers, 2011; Aslani, Samadi Fard, \& Sorani, 2015), infidel parents, emphasis on individualism and personal advancement in schools and universities, and subsequently replacing individual values with collective values, feeling less attachment to the spouse, emotional investment, and low intimacy (Ijtehadi and Vahedi, 2016). It has been estimated that $21-70 \%$ of women and $26-75 \%$ of American men have committed adultery (infidelity) at least once in their married life (Marchese Jeanfreau, 2009). Although some studies have pointed out the subject, there are no accurate statistics on this in Iran. For example, the highest number of domestic homicides (i.e., 30\%) is related to women killed by their husbands due to having an affair (extra-marital relationship) and suspicion (distrust). On the other hand, $22 \%$ of domestic homicides are related to men killed by their wives; in $40 \%$ of cases, women have killed their husbands (Aghagedi, Golparvar, Aghaei, 2018). Kaveh (2008, quoted from Ijtehadi and Vahedi, 2017) concluded that $48 \%$ of women had evidence that their husbands are in a relationship with other women, $27 \%$ of men had sex with someone other than their wives, and $38 \%$ of women thought of having an emotional relationship with another man. Moreover, 13\% of them thought of cheating on their spouses, of which 13\% had an emotional relationship and 2\% had sex. Hawkins AJ, Willoughby BJ, Doherty (2012) concluded that marital infidelity is one of the main reasons for divorce and referral to family counseling clinics. In 2013, The Gallup Institute showed that 91\% of American adults believe that marital infidelity is illegitimate and morally wrong (Asayesh, Farahbakhsh, Delavar, Salimi Bajestani, 2018).

Studies on evolutionary psychology showed gender differences in response to the type of infidelities. From an evolutionary point of view, men evaluate their partner's sexual infidelity as more negative than emotional infidelity and show a stronger reaction to it, while women show the strongest reactions to emotional infidelity (Tagler \& Jeffers, 2013). According to evolutionary studies, people with avoidant attachment styles suffer more from sexual infidelity rather than emotional infidelity (Kelly and Jack, 2006, quoted from Brase, Adair, \& Monk, 2014).

Infidelity tendency can affect the quality of life (QOL) of people. QOL is the level of physical, psychological, and social well-being perceived by the individual, which indicates the degree to which the individual is satisfied with life blessings (Salimzadeh, Iftekhar, Pourreza, and Moghim Beigi, 2007). It includes three dimensions namely emotional, psychological, and social). The emotional dimension means feeling satisfied with life, the psychological dimension means having a rich life, and the social dimension refers to a sense of worthiness in social relationships (Wersebe, Lieb, Meyer, Hofer \& Gloster, 2018). Ezzati and Kakabarai (2016) concluded that QOL could predict marital infidelity. Couple's QOL is an important aspect of family life that forms the psychological health and well-being of couples (Allendorf \& Ghimire, 2013) and has a high correlation with their physical and psychological health. Therefore, it is considered as one of the significant predictors of a successful marriage and avoidance of marital infidelity.

Various studies and theories have been conducted and proposed so far about the factors and reasons for the emergence of extramarital affairs and sexual variety seeking (SVS) and its treatment and prevention methods. One such approach is Acceptance and Commitment Therapy (ACT) with six processes, which lead to psychological resilience. These include acceptance, cognitive defusion (aka deliteralization), self as the observer, a connection to the present, values, and committed action (Hayes, 2005). This treatment method causes people to change their relationship with their inner experiences (Arjmand Qajour and Eghbali, 2018). Verbal interactions in childhood and puberty affect a couple's future relationships. Thus, according to the theory of 
communication framework, as the basis of the ACT approach, language and verbal interactions enrich the experience of love and intimacy, and at the same time cause problems. These problems can be solved using this method (Dahl, Stewart, Martell, Kaplan, 2014). Several studies have examined the effectiveness of ACT on infidelity tendency (Honarparvaran and Barati, 2016), motivation for infidelity of depressed women (Abbassi Cheshmeh Golek-e Sofla and Pour Kamal, 2019), marital satisfaction (Burpee \& Langer, 2005), intimate interpersonal relationships (Baruch, Kanter\& Busch, 2012), reduced marital frustration and increased quality of marital life (Nazari, Fallah Zadeh, Nazar Boland, 2017), marital boredom and commitment (Amidi Simkani, Najjar Pourian, Samavi, 2018), intimacy and forgiveness of couples (Saadatmand, Bassak Nejad, Amanollahi, 2017), self-efficacy and marital satisfaction (Kohodayari Fard, Hejazi, Hosseini Nejad, 2015), depression and infidelity tendency (Folke, Parling, Melin, 2012), increased marital forgiveness and intimacy (Ghassedi, Bagheri, \& Kianmanesh, 2019), decreased depression and QOL (Mofid, Fatehi Zadeh, \& Dorosti, 2017; Azizi \& Ghassemi, 2017), increased QOL in cancer patients (Fashler, Samantha, Weinrib, Aliza, Azam, Katz, 2018), increased QOL in overweight women (Palmeira, Cunha \& Pinto-Guveia, 2019), increased QOL in mothers of children with autism (Zare Bidaki and Jahangiri, 2019), and increased QOL in hypertensive women (Saeedian, Sohrabi, \& Zemestani, 2019).

In the Compassion-Focused Therapy (CFT) approach discussed in the present study, individuals establish a kind relationship with themselves that reduces self-criticism and internalized shame. Neff \& Gilbert are the pioneers in this area. According to this intervention, external thoughts, factors, images, and soothing behaviors must be internalized; in this case, the human mind can also relax in the face of these inner thoughts, as it reacts to external factors (Gilbert, 2014). Besides, in CFT, people are taught not to avoid and suppress their painful feelings; therefore, they can identify and feel compassion toward their experiences (Irons \& Lad, 2017). CFT has been studied in various examples. These include its impact on QOL, self-management, and emotion management (Benzo, Kirsch, Abascal-Bolado, \& Dulohery, 2015), its effectiveness on QOL of adolescent girls with high-risk behaviors (Barghandan, Akbari, Khalatbari, Varasteh, 2018), the tendency to divorce and intimate attitudes of married women (Dasht Bozorgi, Askari, \& Askari, 2017), emotion regulation (emotional self-regulation) of women affected by infidelity (Dash Bozorgi, 2017), QOL (Navab, Dehghani, \& Salehi, 2018), and QOL of patients with multiple sclerosis (MS) (Shaker Nejad, Moazzen, Hamidi, Hashemi, Bazaz Zadeh, \& Badaghi, 2017). To the best of our knowledge, there is no comparative research on the effect of these two therapies on the infidelity tendency and QOL of Iranian couples. In recent decades, infidelity is the most important factor in the increase in divorce rates. Therefore, the necessary solutions should be provided to address it to avoid the material and spiritual costs of the broken marital bond imposed on society. Hence, this study aimed to compare the effectiveness of ACT and CFT on QOL and infidelity tendency, as well as a three-month follow-up, in married students prone to infidelity.

\section{Material and Method}

This is a quasi-experimental research project with an extended research design (pre-test-post-test, with two experimental groups and one control group). The statistical population consisted of all married students aged 20-47 with an average age of 33.5 years $(n=700)$ studying at Islamic Azad University, Sirjan Branch in the 2018-2019 academic year. The convenience sampling method was used to select infidelity-prone married students. In the first step, to determine the cutoff point, since the questionnaire scores are on a spectrum, 30 
married students aged 20-47 studying in technical and humanities colleges were randomly selected as pilots. They were then asked to complete questionnaires on infidelity and QOL. The cutoff score was defined after calculating the scores of these 30 individuals and estimating the mean and standard deviation of the components. This cutoff score was determined on attitudes toward infidelity questionnaire (ATIS) by two standard deviations above the average of the pilot group. The cutoff score of "QOL" was found to be as low as a standard deviation below the average of the pilot group. Then, in the first step, 500 couples aged 20-47 were selected using the convenience sampling method and the ATIS was done as the first screening. In the next step, 183 individuals who got the cutoff score in the QTIQ were selected. Afterward, they entered the second screening stage and completed the QOL Questionnaire. Of those, 78 who got the cutoff score were selected using the questionnaires. Then, 45 of them were randomly selected and divided into three groups, namely two experimental groups and one control group. It is of note that the members completed the profile form, containing the contact number to coordinate the meeting, the location of the meetings. Furthermore, they completed the questionnaires in the post-test and follow-up stage, as well as the consent form for conscious participation in the research. The two experimental groups underwent eight 90-minute sessions (once a week) at the Islamic Azad University, Sirjan Branch, in the second semester of 2018-2019 academic year under group-based ACT and CFT. Meanwhile, the control group did not receive any treatment. At the end of the sessions, members of all three groups re-completed the questionnaires as a post-test after three months in the follow-up phase.

The interventions were based on ethical research criteria, such as reassuring participants about the confidentiality of their information, voluntary participation in research, the researcher's commitment to answering questions about their experiences in practice, and holding workshops based on ACT and CFT therapeutic interventions for the control group after the end of the research.

\section{Tools}

Quality of Life Questionnaire: The WHOQOL-BREF Questionnaire was developed in 1996 by a group of experts from the World Health Organization (WHO) by modifying the items of a 100-item form. It has 26 items that assess four areas, namely physical, psychological, social relationships, and general health, with 7 , 6,3 , and 8 items (a total of 24 items). The first two items measure only the general area of QOL. In the study conducted by Nejat, Montazeri, Holakui Naeini, Kourosh, and Majdzadeh (2006), test-retest reliability was obtained for the following scales: physical health $=0.77$, mental health $=0.77$, social relationships $=0.75$, and environmental health $=0.84$. Internal consistency was also obtained to be greater than 0.7 using Cronbach's alpha for all domains, while it was 0.55 for the range of the social relationship, possibly due to the small number of relevant items or its sensitive items.

ATIS: This scale, which was developed by Mark Whathley (2006), has 12 items each scored on a 7-point scale. Mark Whatley has reported Cronbach's alpha coefficient in the range of $0.87-0.90$, indicating high internal consistency of the scale. Bokam et al. (2009, quoted from Mousavi, 2015) reported that Cronbach's alpha coefficient was 0.88 for the questionnaire. In Iran, the scale was used by Abdullahzadeh (2010, quoted from Mousavi, 2015) among 383 men and women randomly selected and living in Behshahr and Aliabad with a Cronbach's alpha of 0.84 . In a study by Mousavi (2015), Cronbach's alpha was 0.86 , indicating the optimal reliability of the scale. 
Table 1. Session structure based on ACT

\begin{tabular}{|c|c|}
\hline Session 1 & $\begin{array}{l}\text { Establishing a therapeutic relationship, introducing the structure of the meetings and emphasizing secrecy, } \\
\text { adhering to group rules, obtaining the company's consent in the research, conducting a pre-test questionnaire, } \\
\text { familiarity with the ACT approach and case formulation }\end{array}$ \\
\hline Session 2 & $\begin{array}{l}\text { Summarizing the previous session and receiving feedback from students, introduction, and review of experien- } \\
\text { tial avoidance and awareness of its consequences, creating creative hopelessness and giving home assignment }\end{array}$ \\
\hline Session 3 & $\begin{array}{l}\text { Summarizing the previous session and receiving feedback from students, reviewing the assignment of the } \\
\text { previous session, helping clients to identify dysfunctional control strategies and understanding the concept of } \\
\text { "control is problematic", explaining the concept of acceptance and its difference with the concept of submis- } \\
\text { sion, giving home assignment }\end{array}$ \\
\hline Session 4 & $\begin{array}{l}\text { Summarizing the previous session and receiving feedback from students, reviewing the assignment of the } \\
\text { previous session, getting acquainted with the concept of cognitive fusion and fusion with oneself, past, future, } \\
\text { getting acquainted with the concept of cognitive detachment and giving home assignment }\end{array}$ \\
\hline Session 5 & $\begin{array}{l}\text { Summarizing the previous session and receiving feedback from students, reviewing the assignment of the pre- } \\
\text { vious session, explaining mindfulness and introducing mindfulness techniques, body scanning, and mindful } \\
\text { breathing and giving home assignment }\end{array}$ \\
\hline Session 6 & $\begin{array}{l}\text { Summarizing the previous session and receiving feedback from students, reviewing the assignment of the } \\
\text { previous session, explaining the concepts of the self as the observer (self-observer), awareness of different } \\
\text { sensory perceptions and separation from the senses of mental content, and giving home assignment }\end{array}$ \\
\hline Session 7 & $\begin{array}{l}\text { Summarizing the previous session and receiving feedback from students, reviewing the assignment of the } \\
\text { previous session, explaining the concept of values using 80th birthday metaphor, motivation to change and } \\
\text { empower clients to live better, setting goals based on values and giving home assignment }\end{array}$ \\
\hline Session 8 & $\begin{array}{l}\text { Summarizing the previous session and receiving feedback from students, reviewing the assignment of the } \\
\text { previous session, teaching commitment to action, reviewing internal and external barriers, identifying behav- } \\
\text { ior plans according to values and commitment to act on them, summarizing meetings to share experiences of } \\
\text { group members and achievements and fulfilled/unfulfilled expectations, thanking the students for participat- } \\
\text { ing in the group and preparing them for the end of the sessions (i.e., conducting the post-test and ending the } \\
\text { session) }\end{array}$ \\
\hline
\end{tabular}

Table 2. Session structure based on CFT

\begin{tabular}{|l|l|}
\hline \multirow{3}{*}{ Session 1 } & $\begin{array}{l}\text { Establishing initial communication, getting individuals acquainted with the research topic, introducing the struc- } \\
\text { ture of meetings and emphasizing secrecy, adhering to group rules and avoiding judging, blaming and ridiculing } \\
\text { others, obtaining consent to participate in the research, conducting pre-test questionnaire, familiarity with gen- } \\
\text { eral CFT principles, presenting current problems and signs, validating and understanding current problems, and } \\
\text { conceptualizing four areas }\end{array}$ \\
\hline Session 2 & $\begin{array}{l}\text { Summarizing the previous session and receiving feedback from students, teaching mindfulness along with the } \\
\text { physical examination and breathing exercises, recognizing emotion regulation systems (e.g., defense, motiva- } \\
\text { tion, and security), and the role of security system in raising awareness, switching on the security system, and } \\
\text { reducing the hyperactivity of defense and motivational systems, empathy training, giving home assignment }\end{array}$ \\
\hline
\end{tabular}




\begin{tabular}{|c|c|}
\hline Session 3 & $\begin{array}{l}\text { Reviewing the previous session, introducing three brains (old brain, new brain or analyst, and conscious brain } \\
\text { or mind), communicating with the conscious brain or mind, explaining the brain diagram, creating a feeling of } \\
\text { warmth and kindness toward oneself, understanding that others also have flaws and problems, and fostering a } \\
\text { sense of human commonalities (in the face of self-destructive feelings and shame, teaching empathy and giving } \\
\text { home assignment) }\end{array}$ \\
\hline Session 4 & $\begin{array}{l}\text { Reviewing the exercise of the previous session, encouraging subjects to self-knowledge (self-examination) and } \\
\text { examining their personality as a compassionate or uncompassionate person, introducing compassionate reason- } \\
\text { ing and its difference with logical reasoning and techniques of kind attention and sensitivity to their suffering, } \\
\text { being in the present, kind attention and activating the security system by compassionate imagery, and creating a } \\
\text { safe place and giving home assignment }\end{array}$ \\
\hline Session 5 & $\begin{array}{l}\text { Reviewing the exercise of the previous session, introducing compassion behaviors and practicing kind behavior } \\
\text { instead of blaming oneself and others, practicing empathy and sympathy using the torch metaphor, and giving } \\
\text { home assignment }\end{array}$ \\
\hline Session 6 & $\begin{array}{l}\text { Introducing yourself (the dependent self, the imperfect and shamefaced self, the pessimistic self, the isolated } \\
\text { self, the incapable self, the hopeless self, the narcissist self, the sacrificing self, the perfectionist self, and the } \\
\text { kind self) and paying attention to thoughts, feelings, physical symptoms, and behavioral coercion that produces } \\
\text { various selves in different areas of life, encouraging subjects to self-knowledge, examining one's personality as a } \\
\text { compassionate or uncompassionate person according to educational topics, and giving home assignment }\end{array}$ \\
\hline Session 7 & $\begin{array}{l}\text { Reviewing the exercise of the previous session, identifying values in different areas of life using great day } \\
\text { metaphor, prioritizing values, using personal mental images to foster compassion and creating a compassionate } \\
\text { identity through illustration and giving home assignment }\end{array}$ \\
\hline Session 8 & $\begin{array}{l}\text { Reviewing the exercise of the previous session, explaining the acceptance and tolerance of distress by using } \\
\text { metaphors of uninvited guests and daily notes of mental experiences about enduring distress, seeing suffering } \\
\text { and communication with the conscious brain and compassion to the mind, determining the appropriate pattern } \\
\text { of action with kind behavior (structure and challenge) to achieve values and a kind move toward values along } \\
\text { with caring for well-being, and finally summarizing and providing a series of strategies to maintain and apply } \\
\text { this treatment method in everyday life }\end{array}$ \\
\hline
\end{tabular}

\section{Results}

Collected data were analyzed using descriptive and inferential statistics. Table 3 presents the descriptive statistics of the experimental and control groups for each of the measurement steps separately (i.e., pre-test, posttest, and follow-up). The results of a descriptive study of dependent research variables and their components indicate an improvement in QOL scores and its components, except for environmental health component. Moreover, a decrease in infidelity tendency scores is seen in post-test and follow-up compared to pre-test in experimental groups. 
Table 3. Mean and standard deviation of QOL and its dimensions and infidelity tendency according to different evaluation stages for each group membership separately

\begin{tabular}{|c|c|c|c|c|c|c|c|}
\hline \multicolumn{2}{|l|}{ Group } & \multicolumn{2}{|c|}{ Control $(\mathrm{n}=15)$} & \multicolumn{2}{|c|}{$\operatorname{ACT}(n=15)$} & \multicolumn{2}{|c|}{ CFT $(n=15)$} \\
\hline \multicolumn{2}{|l|}{ Variable } & Mean & $\mathrm{SD}$ & Mean & SD & Mean & $\mathrm{SD}$ \\
\hline \multirow{3}{*}{ Physical Health } & Pre-Test & 21.40 & 5.82 & 20.87 & 5.86 & 22.20 & 3.40 \\
\hline & Post-Test & 21.93 & 3.08 & 24.80 & 4.64 & 29.27 & 2.93 \\
\hline & Follow-Up & 19.40 & 4.01 & 29.80 & 3.05 & 33.07 & 1.48 \\
\hline \multirow{3}{*}{ Mental Health } & Pre-Test & 16.00 & 3.25 & 15.53 & 3.35 & 16.80 & 4.24 \\
\hline & Post-Test & 16.33 & 3.61 & 24.60 & 2.79 & 19.53 & 2.85 \\
\hline & Follow-Up & 15.80 & 3.02 & 26.13 & 1.84 & 22.40 & 3.29 \\
\hline \multirow{3}{*}{ Social Interaction Health } & Pre-Test & 8.20 & 1.32 & 9.60 & 1.05 & 9.33 & 1.95 \\
\hline & Post-Test & 9.46 & 1.55 & 12.26 & 1.53 & 10.93 & 1.27 \\
\hline & Follow-Up & 9.26 & 1.22 & 13.60 & 0.98 & 11.80 & 1.56 \\
\hline \multirow{3}{*}{ Environmental Health } & Pre-Test & 25.80 & 6.24 & 25.87 & 5.05 & 24.20 & 5.08 \\
\hline & Post-Test & 25.07 & 4.26 & 27.53 & 5.09 & 27.40 & 4.56 \\
\hline & Follow-Up & 24.07 & 3.03 & 28.13 & 6.20 & 28.80 & 6.17 \\
\hline \multirow{3}{*}{ Overall QOL Score } & Pre-Test & 71.40 & 13.83 & 76.27 & 6.96 & 71.53 & 7.64 \\
\hline & Post-Test & 72.80 & 8.13 & 92.07 & 5.72 & 86.33 & 5.24 \\
\hline & Follow-Up & 68.53 & 8.76 & 101.20 & 5.64 & 94.13 & 7.53 \\
\hline \multirow{3}{*}{ Infidelity Tendency } & Pre-Test & 28.67 & 9.25 & 31.60 & 4.59 & 33.53 & 8.52 \\
\hline & Post-Test & 33.20 & 8.67 & 20.80 & 4.66 & 26.80 & 7.48 \\
\hline & Follow-Up & 32.33 & 7.77 & 14.07 & 1.98 & 18.40 & 5.23 \\
\hline
\end{tabular}

To test the research hypotheses, repeated-measures ANOVA was used, taking into account the assumptions of statistical tests. Before the test, statistical assumptions were examined. The Shapiro-Wilk test showed that the significance level of QOL and its dimensions and infidelity tendency in all stages of the test were $>0.05$. Therefore, it can be concluded that the variable normality assumption is observed in the pre-test, post-test, and follow-up scores in terms of a group membership. Levene's test results for QOL and infidelity tendency variables were $(\mathrm{F}=97.3, \mathrm{P}=0.003)-(\mathrm{F}=2.37, \mathrm{P}=0.053),(\mathrm{F}=1.68, \mathrm{P}=0.019)-(\mathrm{F}=2.47, \mathrm{P}=0.054)$, and $(\mathrm{F}$ $=3.44, \mathrm{P}=0.041)-(\mathrm{F}=1.85, \mathrm{P}=0.013)$ in pre-test, post-test, and follow-up states, respectively. Therefore, the assumption of equal variances in the experimental and control groups is approved. The results of the significance level of Box's M test are greater than 0.05 in all levels of infidelity tendency and QOL analysis, except for the social components component. Therefore, the homoscedasticity assumption of the covariance matrix has been observed in the variables under study, except for the social relations component $(p>0.05)$. Sphericity assumption was examined by Mauchly's test. According to the results, the significance level is $>0.05$ for the 
components of physical health, mental health, and social relationships and $<0.05$ for environmental health components and the overall QOL score. Sphericity of the variance-covariance matrix regarding environmental health and the overall QOL score was not confirmed. Huynh-Feldt test ( $\mathrm{P}>0.075)$ was applied to interpret the findings of environmental health and the overall QOL score. Moreover, the results of Mauchly's test of sphericity for the infidelity tendency variable were rejected $(\mathrm{P}<0.05)$. Since the Greenhouse-Geisser epsilon was larger than 0.075, the Huynh-Feldt test was applied to interpret the findings. Table 4 presents repeated-measures ANOVA results on the effect of the independent variable on QOL and its dimensions.

Table 4. Between-group ANOVA results to investigate the effect of the independent variable (interventions) on QOL and its dimensions

\begin{tabular}{|c|c|c|c|c|c|c|c|}
\hline Sub-Scales & Source & SS & DF & MS & F Value & Sig. & Eta \\
\hline \multirow{3}{*}{ Physical Health } & Time & 81.2155 & 2 & 407.607 & 31.293 & 0.000 & 0.427 \\
\hline & Time*Group & 75.9851 & 4 & 187.996 & 14.433 & 0.000 & 0.407 \\
\hline & Error & 10.13394 & 84 & 13.025 & & & \\
\hline \multirow{3}{*}{ Mental Health } & Time & $948 / 696$ & 2 & 348.474 & 33.163 & 0.000 & 0.441 \\
\hline & Time*Group & 52.0525 & 4 & 131.263 & 12.492 & 0.000 & 0.373 \\
\hline & Error & 88.6672 & 84 & 10.508 & & & \\
\hline \multirow{3}{*}{$\begin{array}{l}\text { Social Interaction } \\
\text { Health }\end{array}$} & Time & 15.2812 & 2 & 76.141 & 41.175 & 0.000 & 0.495 \\
\hline & Time*Group & 33.052 & 4 & 8.263 & 4.468 & 0.003 & 0.175 \\
\hline & Error & 15.3335 & 84 & 1.849 & & & \\
\hline \multirow{3}{*}{$\begin{array}{c}\text { Environmental } \\
\text { Health }\end{array}$} & Time & 74.059 & 1.464 & 50.603 & 2.597 & 0.098 & 0.058 \\
\hline & Time*Group & 15.8306 & 2.927 & 53.579 & 2.750 & 0.052 & 0.116 \\
\hline & Error & 11.77897 & 61.468 & 19.486 & & & \\
\hline \multirow{3}{*}{$\begin{array}{l}\text { Overall QOL } \\
\text { Score }\end{array}$} & Time & 52.25999 & 1.713 & 3093.165 & 66.732 & 0.000 & 0.614 \\
\hline & Time*Group & 3569.496 & 3.426 & 1041.753 & 22.475 & 0.000 & 0.517 \\
\hline & Error & 3352.244 & 71.955 & 46.352 & & & \\
\hline \multicolumn{2}{|c|}{ Physical Health } & 1199.304 & 2 & 599.652 & 25.996 & 0.000 & 0.553 \\
\hline \multicolumn{2}{|c|}{ Mental Health } & 829.881 & 2 & 414.941 & 42.520 & 0.000 & 0.669 \\
\hline \multicolumn{2}{|c|}{ Social Interaction Health } & 184.548 & 2 & 92.274 & 40.147 & 0.000 & 0.657 \\
\hline \multicolumn{2}{|c|}{ Environmental Health } & 124.548 & 2 & 62.274 & 1.199 & 0.312 & 0.054 \\
\hline \multicolumn{2}{|c|}{ Overall QOL Score } & 8459.215 & 2 & 4229.607 & 36.036 & 0.000 & 0.632 \\
\hline
\end{tabular}

According to Table 4, the results of the within-group evaluation indicated a significant difference between pre-test, post-test, and follow-up scores on mental health, physical health, and social relationships with overall QOL scores regardless of group factor. Moreover, the components of mental health, physical health, and social relationships differ significantly in terms of the trend of changes in scores with the overall QOL score from pre-test to post-test and follow-up in the research groups. There was no significant difference in the environmental health component. Moreover, based on between-group ANOVA results, there is a significant difference between the three groups in terms of the QOL variable and its dimensions, except for the environmental health dimension. A pairwise comparison was applied to determine the most effective treatment method, with the results presented in Table 5 . 
Table 5. Pairwise comparisons of QOL variable scores and its dimensions for three groups

\begin{tabular}{|c|c|c|c|c|c|}
\hline Variable & Group (i) & Group (j) & Mean Difference & Error & Sig \\
\hline \multirow{6}{*}{ Physical Health } & \multirow{2}{*}{ Control Group } & $\mathrm{ACT}$ & -4.244 & 1.013 & 0.000 \\
\hline & & CFT & -7.267 & 1.013 & 0.000 \\
\hline & \multirow{2}{*}{ ACT } & Control Group & 4.244 & 1.013 & 0.000 \\
\hline & & CFT & -3.022 & 1.013 & 0.014 \\
\hline & \multirow{2}{*}{ CFT } & Control Group & 7.267 & 1.013 & 0.000 \\
\hline & & $\mathrm{ACT}$ & 3.022 & 1.013 & 0.014 \\
\hline \multirow{6}{*}{ Mental Health } & \multirow{2}{*}{ Control Group } & $\mathrm{ACT}$ & -6.044 & 0.659 & 0.000 \\
\hline & & CFT & -3.533 & 0.659 & 0.000 \\
\hline & \multirow{2}{*}{ ACT } & Control Group & 6.044 & 0.659 & 0.000 \\
\hline & & CFT & 2.511 & 0.659 & 0.001 \\
\hline & \multirow{2}{*}{ CFT } & Control Group & 3.533 & 0.659 & 0.000 \\
\hline & & ACT & -2.511 & 0.659 & 0.001 \\
\hline \multirow{6}{*}{$\begin{array}{l}\text { Environmental } \\
\text { Health }\end{array}$} & \multirow{2}{*}{ Control Group } & $\mathrm{ACT}$ & -2.200 & 1.520 & 0.465 \\
\hline & & CFT & -1.811 & 1.520 & 0.712 \\
\hline & \multirow{2}{*}{ ACT } & Control Group & 2.200 & 1.520 & 0.465 \\
\hline & & CFT & 0.378 & 1.520 & 1.00 \\
\hline & \multirow{2}{*}{ CFT } & Control Group & 1.822 & 1.520 & 0.712 \\
\hline & & $\mathrm{ACT}$ & -0.378 & 1.520 & 1.00 \\
\hline \multirow{6}{*}{$\begin{array}{l}\text { Social Interac- } \\
\text { tion Health }\end{array}$} & \multirow{2}{*}{ Control Group } & $\mathrm{ACT}$ & -2.844 & 0.320 & 0.000 \\
\hline & & CFT & -1.711 & 0.320 & 0.000 \\
\hline & \multirow{2}{*}{ ACT } & Control Group & 2.844 & 0.320 & 0.000 \\
\hline & & CFT & 1.133 & 0.320 & 0.003 \\
\hline & \multirow{2}{*}{ CFT } & Control Group & 1.711 & 0.320 & 0.000 \\
\hline & & ACT & -1.133 & 0.320 & 0.003 \\
\hline \multirow{6}{*}{ Quality of Life } & \multirow{2}{*}{ Control Group } & $\mathrm{ACT}$ & -18.933 & 2.284 & 0.000 \\
\hline & & CFT & -13.089 & 2.284 & 0.000 \\
\hline & \multirow{2}{*}{$\mathrm{ACT}$} & Control Group & 18.933 & 2.284 & 0.000 \\
\hline & & CFT & 5.844 & 2.284 & 0.043 \\
\hline & \multirow{2}{*}{ CFT } & Control Group & 13.089 & 2.284 & 0.000 \\
\hline & & ACT & -5.844 & 2.284 & 0.043 \\
\hline
\end{tabular}

As can be seen in Table 5, both therapies have affected the components of physical health, mental health, social relationships, and the overall QOL score, with the effect of ACT greater than CFT's. Moreover, based on the results, none of the interventions had a significant effect on environmental health.

Table 6. Results of within-group and between-group ANOVA to investigate the effect of independent variables (interventions) on infidelity tendency

\begin{tabular}{|c|c|c|c|c|c|c|c|c|c|}
\hline Variable & \multicolumn{2}{|c|}{ Source } & SS & DF & MS & F value & Sig. & Eta & Power \\
\hline \multirow{3}{*}{$\begin{array}{l}\text { Infidelity } \\
\text { Tendency }\end{array}$} & Time & Huynh-Feldt & 2110.000 & 1.775 & 1188.608 & 25.603 & 0.000 & 0.379 & 1.00 \\
\cline { 2 - 11 } & Time*Group & Huynh-Feldt & 2135.289 & 3.550 & 601.247 & 12.955 & 0.000 & 0.387 & 1.00 \\
\cline { 2 - 11 } & \multicolumn{2}{|c|}{ Error } & Huynh-Feldt & 3461.387 & 74.558 & 46.425 & & & \\
\cline { 2 - 11 } & \multicolumn{2}{|c|}{ Between-Group Factor } & 1931.378 & 2 & 965.689 & 16.378 & 0.000 & 0.438 & 0.999 \\
\hline
\end{tabular}

According to Table 6, the results of the within-group evaluation indicated a significant difference between pre-test, post-test, and follow-up scores for the infidelity tendency variable regardless of group factor. Moreover, there is a significant difference between the trends of changes in infidelity tendency scores from pretest to post-test and follow-up (i.e., the interaction between time and group) in the research groups. Also, based on between-group ANOVA results, there is a statistically significant difference between the three groups in terms of the infidelity tendency variable. A pairwise comparison was performed to determine the most effective treatment method, with the results presented in Table 7. As can be seen in Table 7, both ther- 
apies have influenced infidelity tendency, with the effect of the ACT being greater than CFT's.

Table 7. Pairwise comparisons of infidelity tendency scores for three groups

\begin{tabular}{|c|c|c|c|c|c|}
\hline Variable & Group (i) & Group (j) & Mean Difference & Error & Sig. \\
\hline \multirow{5}{*}{ Infidelity Tendency } & \multirow{3}{*}{ Control Group } & ACT & 9.244 & 1.619 & 0.000 \\
\cline { 2 - 6 } & \multirow{3}{*}{ ACT } & CFT & 5.156 & 1.619 & 0.008 \\
\cline { 2 - 6 } & & Control Group & -9.244 & 1.619 & 0.000 \\
\cline { 2 - 6 } & \multirow{2}{*}{ CFT } & CFT & -4.089 & 1.619 & 0.046 \\
\cline { 2 - 6 } & & Control Group & -5.156 & 1.619 & 0.008 \\
\hline
\end{tabular}

\section{Discussion}

This study was conducted to compare the effectiveness of two approaches, namely ACT and CFT, on QOL and infidelity tendency in students with infidelity tendency. The results showed that both approaches affected promoted QOL and decreased infidelity tendency in students with infidelity tendency. Moreover, the ACT approach has been more effective than CFT in terms of mental health, social health, and QOL. This result is consistent with those obtained from research by Barghandan et al. (2018), Zare Bidaki, and Jahangiri (2018), Fashler et al. (2018), and Shakernejad et al. (2017). Based on the results of the presents study, it can be said that people with infidelity tendency suffer from psychological stress due to obsessive thoughts and preoccupation with someone other than their spouse, lack of common goals with their partner, having marital conflicts and sexual incompatibility, and lack of sexual satisfaction (Ducan, Morgan, and Ducan, 2007). They also become involved in inappropriate social relationships that can affect their psychological and social QOL. Therefore, in the first place, the ACT approach provides individuals with the opportunity to change their relationship with their inner experiences, reduce experiential avoidance of annoying thoughts and feelings related to infidelity, and take action to control them. In the second place, it teaches people how to increase their activity in valuable ways (Gilbert, 2014). ACT focuses more on increasing QOL rather than reducing symptoms, by creating a rich, fulfilling, and meaningful life for the individual as its ultimate goal. People treated with ACT learn how to spend their energy increasing their QOL by accepting annoying internal events instead of avoiding them. They also learn how to identify and adhere to goals that are consistent with their values, and to commit to their goals instead of mixing them with thoughts of infidelity and acting on them by distancing themselves from those thoughts. Side effects and detachment from internal events and actions based on personal values can lead to a person's peace of mind, improved interpersonal relationships, and consequently increased psychological and social QOL.

In this study, CFT caused an increase in the mental, social, and physical QOL of subjects. Creating a non-judgmental, compassionate, flexible, and moment-by-moment relationship can be helpful in a variety of ways using mindfulness techniques in the interpersonal relationships of couples that have the potential to commit infidelity. Taking advantage of mindfulness and creating a sense of adequacy in couples makes them enjoy their existing relationships and use all their efforts in marital relationships based on value-oriented goals, thereby increasing their psychological and social QOL. Based on the results of this study, the effectiveness of CFT has been higher than ACT's in terms of physical health and QOL. This result is in line with the research by Barghandan et al. (2018), Saeidian, Sohrabi and Winter (2019), Palmyra, Kanaha, and Pinto Guaya (2019). To explain this conclusion, we can refer to the results of recent studies on neuroscience and brain 
imaging. They show that compassion expression practice for others and oneself leads to changes in the prefrontal cortex, immune system, and overall health (Lopez, Sanderman, Smink, Zhang, Van Sandren, Rankor, and Scravers, 2015). There was no significant difference between the three groups studied in environmental health. The results showed that none of the interventions had a significant effect on environmental health. The need for clinical trials in ACT and CFT is still in its infancy. As a result, more controlled studies seem necessary in this regard. The results prove the effectiveness of both therapies on the infidelity tendency, with the effect of ACT being more than that of CFT. This result is consistent with the findings of Honar Parvaran and Barati (2016), Abbasi Cheshmeh Golk Sofla and Pourkamali (2018), Honar Parvaran (2014), Burpee \& Langer (2005), and Baruch, Counter, and Bush (2012). Many studies have addressed the relationship between maladaptive schemas, marital satisfaction, and infidelity tendency. These include Aslani, Samadi Fard, and Sudani (2015) and Khodabakhshi Kolaei, Basati Motlagh, Tajik Ismaili, and Rahmatizadeh (2014), to name a few. By identifying behaviors arising from the schema and replacing them with value-oriented behaviors, ACT can affect marital satisfaction and reduce infidelity tendency. ACT leads to the clarification of values in individuals and the identification and clarification of values, enabling to highlight their value system. Hence, it can lower marital infidelity because it is considered a special anti-value by women. On the other hand, people's capacity to recognize their own and others' emotions increases as a result of therapy acceptance and commitment. Thus, it contributes to motivating them to improve the quality of their relationship and more control over their behavior (Honar Parvaran and Barati, 2016). Another effect of ACT is forcing people to stay committed to their marital duties based on their value system. This effect leads to an enhanced QOL in individuals and subsequent strong emotional relationships and adoration. After the improvement of emotional and romantic relationships between couples, the infidelity tendency decreases dramatically. Using the ACT approach, individuals learn that marital satisfaction does not mean that there should be no conflict in the relationship between the couple; instead, they learn that sometimes a satisfying relationship requires a confrontation with and acceptance of negative situations. Using this approach, individuals enjoy higher psychological resilience. As a result, they are better able to cope with the suffering and stress of marital conflict, which can lead to reduced life satisfaction and consequently lower infidelity tendencies. From the ACT's point of view, avoiding internal events creates a harmful process. People with an infidelity tendency may try to get rid of these thoughts completely. The ACT is based on such avoidances to fundamentally solve individual conflicts to experience and distance oneself from thoughts instead of controlling them. By identifying behaviors arising from the schema and replacing them with value-oriented behaviors, ACT can affect marital satisfaction and reduce infidelity tendency (Aslani, Samadi Fard, and Sudanese, 2015) (Kolaei Divorce, Absolute Basati, Tajik Ismaili, and Rahmatizadeh, 2014).

This study showed that using CFT could reduce the infidelity tendency. According to the CFT approach, there is a correlation between compassion for others and self-compassion. Self-compassion involves the expansion of love, affection, and understanding of one's own pain and suffering (Neff, 2009). The results suggest that unkind behavior and lack of self-compassion will lead to unkind and compassionate behavior toward others (Neff, 2009). In contrast, self-compassion leads to kind and compassionate behavior toward others. Neff \& Beretras (2013) found that people with higher self-compassion ratings showed more positive behaviors in their relationships, which could be effective in preventing infidelity. Also, in CFT, by taking advantage of the distress tolerance training in the passion dimension, people learn that they should not suppress their painful feelings. Therefore, in the first step, they can identify their experience and be compassionate about it (Irons and 
Lad, 2017). Having self-compassion activates people's security system. Moreover, self-compassion exercises focus on relaxation and mindfulness, which will play a significant role in mental relaxation, stress reduction, and negative thoughts (Gilbert, 2014; Neff \& Germer, 2013). As a result of these exercises, marital conflicts and the probability of infidelity tendency is declined. Moreover, research has determined the relationship between insecure attachment styles and infidelity tendency (Ghafouri, Golparvar, and Mehdi Zadegan, 2009). In this regard, Ho, Chen, Bond, Hui, Chan, and Friedman (2012) concluded that there is a link between insecure attachment styles and people's low commitment to marital relationships. Based on attachment theory, it can be stated that people with insecure attachment styles have self-criticism and internalized shame. Therefore, using self-compassion techniques, CFT can lower people's self-criticism and internalized shame and set the stage to reduce infidelity tendency by modifying attachment styles. Self-compassion leads to a clear and balanced awareness of current experiences and causes the painful aspects of an experience not to be overlooked and not to become a recurring obsession (Neff \& Mac Gehee, 2010). Self-compassion training leads to acceptance and kindness to oneself and others. Consequently, when faced with unpleasant thoughts and feelings (such as infidelity tendency), couples show positive self-regulation that leads to the promotion of sincere attitudes toward a more purposeful life and allows for attractiveness, decent behavior, and trust between married people with an increase in self-esteem in marital relationships. The more the self-compassion is, the more gratification, satisfaction, and positive emotions are provided in the married life (Askari and Askari, 2017).

Marital infidelity can negatively affect a couple's QOL and psyche. Given the increased potential for infidelity among Iranian couples, the need to design a series of interventions that can prevent infidelity and the resulting damage that can put the deathblow on the whole body of society is increasingly felt. Using these preventative measures allows helping a healthy life and QOL of couples.

One of the limitations of this study is the statistical population, which was consisted of married students aged 20-47 years studying at the Islamic Azad University, Sirjan Branch. Thus, the generalizability of the obtained results was not adequate. So, it is suggested to conduct the present research in other universities of the country and to examine the similarities and differences between the results of that research and those of the present study.

Declaration of Conflicting Interests: The author(s) declared no potential conflicts of interest with respect to the research, authorship, and/or publication of this article.

Funding: The authors received no financial support for the research, authorship, and/or publication of this article.

Acknowledgements: We are grateful to all the participants who have contributed to this study.

\section{References}

Abbasi Cheshmeh Golek-e Sofla, A., \& Pourkamali, T. (2018). The Effect of ACT on Motivation for Infidelity of Depressed Women in Shahreza, 2nd International Conference on Innovation and Research in Educational Sciences, Management and Psychology, Tehran, Soroush Hekmat Mortazavi Center for Islamic Studies and Research.

Aghagedi, P., Golparvar, M., Aghaei, A., \& Khayatan, F. (2018). The Effects of Forgiveness-Based Mindfulness Therapy and Emotionally Focused Therapy on Depression and Resiliency in Women Affected by 
Their Husbands' Infidelity. Community Health Journal, 12(1), 1-11.

Allendorf, K., \& Ghimire, D. J. (2013). Determinants of marital quality in an arranged marriage society. Social Science Research, 42(1), 59-70.

AmidiSimkani, R., \& Najjarpourian, S. Samavi, A. (2017). The Effectiveness of the ACT Approach Training on the Boredom and Marital Commitment of Married Women. Clinical Psychology and Counseling Research, 7. 2. 55-68.

Arjmandghujur, K., \& Eghbali, A. (2018). A comparing of two schema therapy and acceptance and commitment therapy attitudes effectiveness on early maladaptive schema in Methamphetamine addicts. Rooyeshe Ravanshenasi, 7, 151-78

Asayesh, M., Farahbakhsh, K., Delavar, A., \& Salimi Bajestani, H. (2018). Experiences and Cognitive Responses of Women Affected by Spouse's Infidelity: A Phenomenological Study. Qualitative Research in Health Sciences, 7. 2. 214-229.

Askary, M., \& Askary, P. (2017). The Effecttivness of self-compassion on the intimacy attitudes and divorce tendency of Women refering to family counselling. JSR, 18(1), 38-45.

Aslani, K., Samadi Fard, A., \& Sudani, Mansour (2015). Testing Early Maladaptive Schemas, Disconnection/ Rejection Domain, and Marital Satisfaction with the Mediating Role of Insecure Attachment Style and Depression. Family Counseling and Psychotherapy, 5. 1. 94-114.

Azizi, A., \& Ghasemi, S. (2017). Comparison of the Effectiveness of Three Approaches, Solution-Focused, Cognitive-Behavioral, and ACT on Depression and QOL in Divorced Women. Counseling Culture and Psychotherapy, 8. 29. 207-236.

Barghandan, S., Akbari, B. Khalatbari, J., \& Varasteh, A. (2018). The Effect of Compassion-Focused Therapy (CFT) on Adjustment and Happiness of Students with High-Risk Behaviors. Child Mental Health, 5. 2. 142-153.

Barta, W. D., \& Kiene, S. M. (2005). Motivations for infidelity in heterosexual dating couples: The roles of gender, personality differences, and sociosexual orientation. Journal of Social and Personal Relationships, 22(3), 339-360

Baruch, D., Kanter, J., \& Busch, A. (2012). Acceptance and commitment therapy: enhancing the relationships. Journal of clinical case studies, 8(3), 241-257.7

Batink, T., Bakker, J., Vaessen, T., Kasanova, Z., Collip, D., van Os, J., \& Peeters, F. (2016). Acceptance and commitment therapy in daily life training: A feasibility study of an mHealth intervention. JMIR mHealth and uHealth, 4(3), e103.

Benzo, R., Kirsch, J., Abascal-Bolado, B., \&Dulohery, M. M. (2015). D103 copd: focus on research and patient care: impact of self-compassion on quality of life, emotions and self-management abilities in copd. american journal of respiratory and critical care medicine, 191, 1.

Brase, G. L., Adair, L., \& Monk, K. (2014). Explaining sex differences in reactions to relationship infidelities: Comparisons of the roles of sex, gender, beliefs, attachment, and sociosexual orientation. Evolutionary Psychology, 12(1), 147470491401200106.

Burpee, L. C., \& Langer, E. J. (2005). Mindfulness and marital satisfaction. Journal of AdultDevelopment, 12(1), 43-51.

Dahl, J., Stewart, I., Martell, C., \& Kaplan, J. S. (2014). ACT and RFT in relationships: Helping clients deepen intimacy and maintain healthy commitments using acceptance and commitment therapy and relational 
frame theory. New Harbinger Publications.

Dasht-e Bozorgi, Z. (2017). The Effect of Self-Compassion-Based Interventions on Feelings of Loneliness and Emotional Regulation in Women Affected by Marital Infidelity. Knowledge and Research in Applied Psychology, 18. 2. 72-79.

Dasht-e Bozorgi, Z.; Asgari, M., \& Asgari, P. (2017). The Effectiveness of Self-Compassion Training on the Tendency to Divorce and the Sincere Attitudes of Married Women Who Refer to the Family Counseling Center. Applied Psychology, 18. 1. 38-45.

Docan-Morgan, T., \& Docan, C. A. (2007). Internet infidelity: Double standards and the differing views of women and men. Communication Quarterly, 55(3), 317-342.

Ezzati, N., \& Kakabarai, K. (2016). Prediction of Marital Infidelity Based on the Quality of Marital Life and Five Major Personality Factors. Nations Research, 1. 9. 75-82.

Fashler, S. R., Weinrib, A. Z., Azam, M. A., \& Katz, J. (2018). The use of acceptance and commitment therapy in oncology settings: a narrative review. Psychological reports, 121(2), 229-252.

Folke, F., Parling, T., \& Melin, L. (2012). Acceptance and commitment therapy for depression: A preliminary randomized clinical trial for unemployed on long-term sick leave. Cognitive and Behavioral Practice, 19(4), 583-594.

Gafouri, V. M., Golparvar, M., \& Mahdizadegan, I. (2009).A study of attachment styles and religious attitudes as predictors of success or failure of marital relationship. Journal of Research in Behavioural Sciences, 7 , 2, 143-153.

Ghasedi, M., Bagheri, F., \& Kiamanesh, A. (2019). Comparison of the Effectiveness of Group Therapy based on Mindfulness and Acceptance and Commitment Techniques (ACT) on Forgiveness, Emotional Regulation and Marital Intimacy. Bioethics Journal, 8(29), 87-98.

Gilbert, P. (2014). The origins and nature of compassion focused therapy. British Journal of Clinical Psychology, 53(1), 6-41.

Hawkins, A. J., Willoughby, B. J., \& Doherty, W. J. (2012). Reasons for divorce and openness to marital reconciliation. Journal of Divorce \& Remarriage, 53(6), 453-463.

Hayes, S. C. (2005). Get out of your mind and into your life: The new acceptance and commitment therapy. New Harbinger Publications.

Ho, M. Y., Chen, S. X., Bond, M. H., Hui, C. M., Chan, C., \& Friedman, M. (2012). Linking adult attachment styles to relationship satisfaction in Hong Kong and the United States: The mediating role of personal and structural commitment. Journal of Happiness Studies, 13(3), 565-578.

Honarparvaran, N. (2014). Investigating the Effectiveness of ACT Approach on Forgiveness and Marital Adjustment in Women Affected by Husband's Infidelity. Women and Society, 3, 135-150.

Honarparvaran, N., \& Barati, B. (2016). The Effectiveness of the ACT Approach on Marital Infidelity and Internet Addiction Among Women. Fifth National Conference on Psychology, Counseling, and Social Work.

Ijtihad, M., \& Vahedi, G. (2016). A Sociological Study of the Potential of Marital Infidelity and the Factors Influencing it Among Public and Private Sector Employees. Iranian Journal of Sociology, 17. 4. 105-138.

Irons, C., \& Lad, S. (2017). Using compassion focused therapy to work with shame and self-criticism in complex trauma. Australian Clinical Psychologist, 3(1), 1743.

Kemer, G., Bulgan, G., \& Yıldız, E. Ç. (2016). Gender differences, infidelity, dyadic trust, and jealousy among married Turkish individuals. Current Psychology, 35(3), 335-343. 
Khayyat, I., Attari, Y., \& Karaei, A. (2018). Infidelity Tendency Prediction Based on Personality Traits and Attachment Styles in Married People. Social Psychology Research, 8. 31. 87-102.

Khodabakhshi Kolaei; A., Basati Motlaq, T., Tajik Ismaili, A., \& Rahmatizadeh, M. (2014). Early Maladaptive Schemas and Sincere Attitudes in Unfaithful Married Men. Iranian Journal of Psychiatric Nursing (IJPN), 2. 3. 12-23.

KhodayariFard, M., Hejazi, E., \& Hasaninezhad, N. (2015). The effectiveness of acceptance and commitment consultation (ACT) on self-efficacy and marital satisfaction substance using married women with children. J ApplPsychol Res, 6(2), 61-75.

López, A., Sanderman, R., Smink, A., Zhang, Y., van Sonderen, E., Ranchor, A., \& Schroevers, M. J. (2015). A reconsideration of the Self-Compassion Scale's total score: self-compassion versus self-criticism. PloS one, 10(7), e0132940.

Marchese Jeanfreau, M. (2009). A qualitative study investigating the decision-making process of women's participation in marital infidelity (Doctoral dissertation, Kansas state university).

Mofid, V., Fatehizadeh, M., \& Dorosti, F. (2017). The Effectiveness of ACT on Depression and QOL of Criminal Women Prisoners in Isfahan. Strategic Research on Security and Social Order. 17-30.

Mousavi, A. (2015). Predicting the Attitude of Infidelity Based on the Feeling of Loneliness in Married Students. First National Congress on the Healthy Family, Shahid Chamran University of Ahvaz.

Navab, M., Dehghani, A., \& Salehi, M. (2018). The Effect of Group-Based CFT on QOL and Changes in the Goals and Priorities of Mothers of Children with Attention-Deficit/Hyperactivity Disorder (ADHD). Child Mental Health, 5. 1. 127-137.

Nazari, A., Fallahzadeh, H., \& Nazar Boland, N. (2017). The Effectiveness of ACT on Women's Frustration and Marital Quality. Applied Psychology, 11. 3. 354-433.

Neff, K. D. (2009). The role of self-compassion in development: A healthier way to relate to oneself. Human development, 52(4), 211.

Neff, K. D., \& Beretvas, S. N. (2013). The role of self-compassion in romantic relationships. Self and Identity, 12(1), 78-98.

Neff, K. D., \& Germer, C. K. (2013). A pilot study and randomized controlled trial of the mindful self $\square$ compassion program. Journal of clinical psychology, 69(1), 28-44.

Neff, K. D., \& McGehee, P. (2010). Self-compassion and psychological resilience among adolescents and young adults. Self and identity, 9(3), 225-240.

Neff, K. D., \& Vonk, R. (2009). Self $\square$ compassion versus global self $\square$ esteem: Two different ways of relating to oneself. Journal of personality, 77(1), 23-50.

Nejat, S., Montazeri, A., Holakoui Naeini, K., \& Mohammad K, Majdzadeh, S. (2006). Standardization of the World Health Organization Quality of Life Brief Version (WHOQOL-BREF): The Translation and Psychometry of the Iranian Species. The Quarterly Journal of the School of Public Health and Institute of Public Health Research, 4. 4. 1-12.

Nowak, N. T., Weisfeld, G. E., Imamoğlu, O., Weisfeld, C. C., Butovskaya, M., \& Shen, J. (2014). Attractiveness and spousal infidelity as predictors of sexual fulfillment without the marriage partner in couples from five cultures. Human Ethology Bulletin, 29(1), 18-38

Palmeira, L., Cunha, M., \& Pinto-Gouveia, J. (2019). Processes of change in quality of life, weight self-stigma, body mass index and emotional eating after an acceptance-, mindfulness- and compassion-based group 
intervention (Kg-Free) for women with overweight and obesity. Journal of Health, 24(8):1056-1069.

Saadatmand, K., Basak, N., \& Amanollahi, A. (2017). The effectiveness of an acceptance and commitment-based couple therapy in intimacy and forgiveness among couples. Family Psychology, 4, 1, 41-52.

Saeidian, K., Sohrabi, A., \& Zemestani, M. (2019). The Effectiveness of CFT on Blood Pressure and QOL in Hypertensive Women. Journal of Ilam University of Medical Sciences, 27,1, 161-169.

Salimzadeh, H., Eftekhar, H., Pourreza, A., \& Moghim Beigi, A. (2007). Re-Employment and QOL Characteristics. Social Welfare Quarterly, 1. 66. 611-681.

Shakernejad, S., Moazzen, N., Hamidi, M., Hashemi, R., Bazazzadeh, N., \& Badaghi, M. (2017). The Effects of ACT on Psychological Distress, Marital Satisfaction, and QOL in Women with Multiple Sclerosis (MS). Journal of Health and Care, 19, 1, 7-17.

Tagler, M. J., \& Jeffers, H. M. (2013). Sex differences in attitudes toward partner infidelity. EvolutionaryPsychology, 11(4),147470491301100407.

Weeks, G. R., Gambescia, N., \& Jenkins, R. E. (2003). Treating infidelity: Therapeutic dilemmas and effective strategies. WW Norton \& Co.

Wersebe, H., Lieb, R., Meyer, A. H., Hofer, P., \& Gloster, A. T. (2018). The link between stress, well-being, and psychological flexibility during an Acceptance and Commitment Therapy self-help intervention. International Journal of Clinical and Health Psychology, 18(1), 60-68.

Zare Bidaki, Z., \& Jahangiri, M. (2019). The Effect of ACT on the QOL of Mothers of Children with Autism. Journal of Women and Society, 10, 37, 29-44.

Zeigler-Hill, V., Green, B. A., Arnau, R. C., Sisemore, T. B., \& Myers, E. M. (2011). Trouble ahead, trouble behind: Narcissism and early maladaptive schemas. Journal of Behavior Therapy and Experimental Psychiatry, 42(1), 96-103. 